\title{
The Relationship between Clinical Instructor's Communication Satisfaction and Their Organizational Commitment at the Faculty of Nursing- Cairo University
}

\author{
Sahar Hassan Aly EL Banan and Amal Hebashy Elewa \\ Lecturer of Nursing Administration, Nursing Administration Department, Faculty of Nursing, Cairo University \\ Egypt
}

\begin{abstract}
:
Background: Worker's communication satisfaction begins to be an important factor in determining organizational commitment of employees. Employees tend to feel happy and loyal to the organization if they have a good communication relationship.

Aim: The main purpose of this study was to examine the relationship between clinical instructor's Communication satisfaction and their organizational commitment.

Design: Descriptive correlational design was utilized in this study.

Setting: The present study was carried out at the faculty of nursing-Cairo University.

Subjects: A convenient sample of (125) clinical instructors who are working at the faculty of nursing-Cairo University and are willing to participate in the study constituted the study sample.

Tools: Data of the present study were collected through utilizing the following two tools: Communication Satisfaction Questionnaire (CSQ) and Organizational Commitment Questionnaire (OCQ).

Results: The findings of the present study indicated that there was an explicit positive relationship between clinical instructor's communication satisfaction and their organizational commitment, there was a statistical significant correlation between clinical instructor's satisfaction with the current position and communication satisfaction and their organizational commitment.

Recommendations: replication of this study is recommended in private and governmental educational organizations, organizations can improve communication by providing opportunities for training programs and workshops for continues improvement with the focus on effective communication and future research studies conducted to investigate the relationship between communication satisfaction and other variables as job satisfaction, turnover and productivity .
\end{abstract}

Keywords: Communication satisfaction and organizational commitment.

\section{Introduction}

Today the world has become more competitive compared to few years ago, increasing globalization, labor forces changes, traditional organization forms elimination and benchmarking are occurring (Carr, 2005). The days where technology was not available, and organization operations were smaller in scale and localized were no longer present. In the past employees were considering the salary as the main criteria while choosing and remaining in a job. In the present with greater access to information, educated employees look beyond the salary, they look at other areas before they decide to enter or exit a job. These areas include a relationship with supervisor and working environment. Thus, it is important to ensure that organizations stay competitive to keep up their employees, and address the right issues to keep the employees satisfied. (Zhen, 2013)

Communication is central to management practice. Managers spend a long time of their work engaged in communication. Communication is an essential aspect for the functioning of organizations. Organizations are no longer focus only on bureaucratic and formal management and communication; the interpersonal relationships among employees within the organization are increasingly paid attention to. Employees do not only formally exchange information related to work and their organization, but also communicate about themselves and their feelings. They are communicating about topics that don't relate to work (Yan, 2011). Communication plays an essential role within any organization, whether this organization is a business, nonprofit, educational, or governmental organization. Effective communication has a great effect on various components in an organization and can help in leading to greater success for the organization (Steingrimsdottir, 2011).

Balakrishnan and Masthan (2013) reported that internal communication is the formal and informal exchange of information between management and employees within the organization. Communications are the technology and systems used for exchanging messages. Organizational communication focuses on connecting employees, groups and organization to facilitate smooth operation and impulsive cooperation. It is instrumental 
in facilitating supportive employees. (De Ridder \& Jan, 2004). Communications may include newsletter, circulation materials, surveys, emails, suggestion boxes, meetings, in-house television, face-to-face relations, email, hotlines, Internet, telephone calls, videoconferences, memos, letters, notice boards, formal presentations and reports (DeBussy, Ewing \& Pitt, 2003; Goodman \& Truss, 2004; Baumruk, Gorman \& Gorman, 2006 and Yates, 2006)

An effective communication should be the goal of any organization. Good communication creates a healthy environment in which the employees committed, trusted, motivated and this help the organization to succeed and move forward. However lack of communication can lead to distracted and de-motivated employees who feel a lack of trust in the organization and its management, and this in turn leads to the malfunctioning of the organization (Hayase, 2009 and Moyer, 2011). Communication satisfaction has received great attention in the past twenty years. Understanding communication satisfaction can offer the organization an ability to better improve the overall job satisfaction. Communication satisfaction is an affective appraisal of the employees to the communication practices of the organization. (Bourque, 2009 and Liang \&Back, 2011).

Organizational commitment is defined as employee's attitude towards the entire organization that he or she works in. It is the sense of honesty that an employee has towards his or her employer (Sharma, 2015). Organizational commitment is the degree to which an employee establishes a strong link with the organization and wants to continue active participation in it (Newstrom, 2007). Organizational commitment is the psychological bond of the employees to the organization, which include a sense of job involvement, loyalty, and a belief in the values of the organization. It is characterized by employee's acceptance to the values and goals of the organization, their willingness to exert an effort on behalf of the organization and their wish to support organizational membership (Iqpal, 2010).

Various researches showed that there is a positive relationship between communication satisfaction of employees and their organizational commitment. Worker's communication satisfaction begins to be an important factor in determining organizational commitment of employees. Employees tend to feel happy and loyal to the organization if they have a good communication relationship. Organization has an important role in ensuring that the staffs are satisfied with the communication pattern within it (Ahmad, 2004; Alanezi, 2011 and Lew, 2011). Communication satisfaction is very important issue to be studied in current workforce, to understand the attitude and behavior of employees. It has a great effect on organizational commitment, which will influence the success and reputation of an organization. Communication satisfaction plays an important role in ensuring employees' satisfaction and organizational commitment (Miller, 2015).

\section{Significance Of Study}

Today, the way we communicate with our coworkers, teams, and supervisors has changed from the past few decades. Communication satisfaction has received a great attention in the past twenty years. Understanding employee's communication satisfaction can enhance the overall job satisfaction. Good communication practice is very essential for a smooth operation of the organization (Communication theory.org, 2010 and Liang \&Back, 2011).

Managers spend more than 75 percent of their time in communication. Previous researches showed that internal communication is very important. Researchers found that there is a positive relationship between the time spent on communication and job satisfaction. Therefore organizations spend significant human and financial resources for developing an effective internal communication system (Farahbod, Salimi and Dorostkar, 2013).

Employee's commitment towards the work and organization is necessary. The management can get the employee commitment to organization through improvement of the quality of communication. Studies have documented that communication satisfaction affects organizational commitment. We hope that this study provided an insight to managers on how communication satisfaction can impact employee's organizational commitment. This study can create an understanding of whether there is a relationship between clinical instructor's communication satisfaction and their organizational commitment. Organizations can benefit from this study as they are able to know how to improve the interpersonal communication structure among their employees and to develop better strategies to maintain their workers' commitment.

\section{The aim of the study:}

\section{Study Methods}

This study aimed to examine the relationship between clinical instructor's communication satisfaction and their organizational commitment.

\section{Research questions:}

The following research questions were guided the research study:

Q1: Is there a relationship between clinical instructor's communication satisfaction and their organizational commitment? 
Q2: Is there a significant relationship between the level of communication satisfaction among clinical instructors and the years of experience in their current position?

\section{Sample:}

A convenient sample of (125) out of (143) clinical instructors who are working at the faculty of nursing- Cairo University and willing to participate in the study constituted the study sample. Clinical instructor's number in each department represents the majority of clinical instructors who are working in this department.

\section{Design:}

Descriptive correlational design was utilized in this study to examine the relationship between clinical instructor's communication satisfaction and their organizational commitment. Cross sectional design was utilized.

\section{Study setting:}

The study was carried out at the Faculty of Nursing- Cairo University. It was established in 1963, the main purpose of establishing to start the study of nursing at the university level in order to graduate a qualified professional nurse who is competent and capable to work among the health care team at different health and educational organizations in the community. Faculty of Nursing, Cairo University obtained national accreditation from the National organization of quality improvement and accreditation.

\section{Tools:}

Data of the current study were gathered through utilizing the following tools:

1. Communication Satisfaction Questionnaire (CSQ) developed by: Downs \& Hazen (1977). It is a self administered questionnaire that consisted of two parts

a. The $1^{\text {st }}$ part was the socio demographic data that included: age, gender, educational level, years of experience at the faculty and years of experience at the current position.

b. The $2^{\text {nd }}$ part was the Communication Satisfaction Questionnaire (CSQ) that consisted of 37 items that distributed as follows: superior- subordinate communication (20 items), quality of information (12 items), Opportunity to upward communication (3 items) and reliability of information ( 2 items). Cronbach alphas for these factors were $0.94,0.88,0.89$, and 0.83 , respectively. The scoring system was a Five-point Likert scale with " 1 " being "strongly disagree" and "5" being "strongly agree".

2. Organizational Commitment Questionnaire (OCQ) developed by Mowday, Steers \& Porter (1979). It is a self administered questionnaire that consisted of (17 items) phrased positively and negatively and require reverse scoring. The reliability coefficient of the questionnaire was 0.90 Cronbach's alpha value. The scoring system was a Five-point Likert scale with "1" being "strongly disagree" and "5" being "strongly agree".

\section{Tools validity:}

Data collection tools were handed to group of experts in nursing administration department to test its content validity and to assess the coverage, relevancy and clarity of items. Based on their recommendations, necessary modifications were made.

\section{The pilot study:}

Once the questionnaires modified and constructed, a pilot study was conducted to test applicability and clarity of the questionnaires and to estimate the time needed to fill them. The questionnaires were handed to the clinical instructors and collected at the same time. Adjustments were made to the questionnaires based on the feedback gathered from the pilot. Time consumed for filling the questionnaire was ranged between $25-30$ minutes.

\section{Ethical considerations:}

Permissions were gained from the dean of the Faculty of Nursing- Cairo University and the department heads; also oral permission was taken from clinical instructors. They were acquainted that their participation is voluntary and informed that their responses will be confidential.

\section{Procedures:}

The aim of the study was explained to study subjects who are working at the faculty of nursing- Cairo University and who are volunteering to participate in the study. The tools were distributed to the clinical instructors while they were on duty, with explanation of the way of answering. The time consumed to fill the 
The Relationship Between Clinical Instructor's Communication Satisfaction And Their...

questionnaires ranged from 25 to 30 minutes. Data were collected during 2016 with duration of three months (March to May).

Statistical analysis: data were inserted and analyzed through using the statistical program of Statistical Package for the Social Sciences (SPSS) version16. Data were analyzed using frequency and percentage, measures of mean and standard deviations, bivariate correlation and independent T- test. Significance was adopted at $\mathrm{p}<0.05$ for interpretation of results of tests of significance.

\section{Results}

Table (1) Frequency Distribution of Clinical Instructors Demographic Characteristics $(\mathrm{N}=125)$

\begin{tabular}{|c|c|c|}
\hline Clinical instructors characteristics & $(\mathbf{N})$ & $\%$ \\
\hline \multicolumn{3}{|l|}{ 1-Age (Years) } \\
\hline 1. Less than 25 years & 5 & 4 \\
\hline 2. $25-30$ years & 87 & 69.4 \\
\hline 3. More than 30 years & 33 & 26.6 \\
\hline \multicolumn{3}{|l|}{$\begin{array}{ll}\mathrm{X}=2.2240 & \mathrm{SD}=.50584\end{array}$} \\
\hline \multicolumn{3}{|l|}{ 2-Sex: } \\
\hline 1.Male & 33 & 26.4 \\
\hline 2. Female & 92 & 73.6 \\
\hline \multicolumn{3}{|l|}{ 3-Educational level: } \\
\hline 1. Baccalaureate degree & 56 & 44.8 \\
\hline 2. Master degree & 69 & 55.2 \\
\hline \multicolumn{3}{|l|}{ 4-Years of experience in the faculty: } \\
\hline 1. Less than 2 years & 13 & 10.4 \\
\hline 2. $2-5$ years & 57 & 45.6 \\
\hline 3. $6-9$ years & 35 & 28.0 \\
\hline 4. More than 9 years & 20 & 16.0 \\
\hline \multicolumn{3}{|l|}{$\mathrm{X}=2.4960 \mathrm{SD}=.88558$} \\
\hline \multicolumn{3}{|l|}{ 5-Years of experience in your current position: } \\
\hline 1. Less than 2 years & 31 & 24.8 \\
\hline 2. $2-5$ years & 68 & 54.4 \\
\hline $3.6-9$ years & 20 & 16.0 \\
\hline 4. More than 9 years & 6 & 4.8 \\
\hline $\mathrm{SD}=.77767$ & & \\
\hline
\end{tabular}

Table (1) shows that $(73.6 \%)$ of clinical instructors were female and $(55.2 \%)$ of them had a master degree in nursing. As regards to the age of respondents, the mean age was $2.2240 \pm .50584$, while the mean age of their years of experience at the faculty was $2.4960 \pm 88558$ compared to $2.0080 \pm .77767$ years of experience in the current position.

Table (2) Frequency Distribution of Clinical Instructors Satisfaction Regarding to Their Current Position

\begin{tabular}{|l|l|l|}
\hline Levels of satisfaction & $(\mathbf{N})$ & \% \\
\hline 1. Very dissatisfied & 11 & 8.8 \\
2. Dissatisfied & 6 & 4.8 \\
3. Indifferent & 17 & 13.6 \\
4. Satisfied & 78 & 62.4 \\
5. Very dissatisfied & 13 & 10.4 \\
\hline
\end{tabular}

The previous table shows that the highest percentage $(62.4 \%)$ of clinical instructors was satisfied with their current position and the lowest percentage (4.8\%) of them was dissatisfied.

Table (3) Correlation between Communication Satisfaction Subscales as Perceived by Clinical Instructors and Their Organizational Commitment

\begin{tabular}{|l|l|l|l|l|}
\hline Communication satisfaction subscales & $\mathrm{X}$ & $\mathrm{SD}$ & \multicolumn{2}{|l|}{ Organizational commitment } \\
\cline { 4 - 5 } & & & $\mathrm{r}$ & $\mathrm{P}$ \\
\hline 1. Superior- subordinate communication & 50.633 & 9.829 & .579 & .000 \\
\hline 2. Quality of information & 25.232 & 7.041 & .393 & .000 \\
\hline 3. Opportunity to upward communication & 6.152 & 2.059 & .284 & .000 \\
\hline 4. Reliability of information & 4.784 & 1.132 & .311 & .001 \\
\hline
\end{tabular}

This table shows that there is a statistical significant correlation between clinical instructor's organizational commitment and all the subscales in communication satisfaction with $p$ value $(0.000)$ 
The Relationship Between Clinical Instructor's Communication Satisfaction And Their...

Table (4) Correlation between Communication Satisfaction as Perceived by Clinical Instructors and Their Organizational Commitment

\begin{tabular}{|l|l|l|}
\hline Variables & \multicolumn{2}{|l|}{ Organizational commitment } \\
\hline Communication satisfaction & $\mathrm{r}$ & $\mathrm{P}$ \\
\cline { 2 - 3 } & .558 & $\mathbf{. 0 0 0}$ \\
\hline
\end{tabular}

A bivariate correlation was conducted to investigate the relationship between communication satisfaction and organizational commitment. This table indicates that there is a statistical significant positive correlation between clinical instructor's communication satisfaction and their organizational commitment. $(\mathrm{p}=.000)$

Table (5) Correlation between Clinical Instructors Demographic Characteristics and Their Communication Satisfaction and Organizational Commitment

\begin{tabular}{|l|l|l|l|l|l|l|l|l|}
\hline Demographic characteristics & \multicolumn{3}{l|}{ Communication satisfaction } & \multicolumn{3}{l|}{ Organizational commitment } \\
\hline & $\mathrm{X}$ & $\mathrm{SD}$ & $\mathrm{r}$ & $\mathrm{p}$ & $\mathrm{X}$ & $\mathrm{SD}$ & $\mathrm{r}$ & $\mathrm{p}$ \\
\hline 1. Age & & & & & & & & \\
- Less than 25 years & 84.800 & 15.056 & & & 37.200 & 5.495 & \\
- 25- 30 years & 86.011 & 16.446 & .352 & .084 & 36.804 & 4.584 & \\
-More than 30 years & 89.181 & 18.296 & & & 39.060 & 5.459 & \\
\hline 2. Years of experience in the faculty & 2.496 & .8855 & .827 & .020 & 2.496 & .885 & .167 & .063 \\
\hline 3. Years of experience in your current & 2.008 & .7776 & .768 & .027 & 2.008 & .777 & .060 & .505 \\
position & & & & & & & & \\
\hline
\end{tabular}

This table represents the correlation between clinical instructor's demographic characteristics and their communication satisfaction and organizational commitment. It is clear that there is a statistical significant correlation between clinical instructor's communication satisfaction and their years of experience in the faculty $(p=.020)$ and years of experience in the current position $(p=.027)$. Also, the table shows a statistical significant correlation between the age of respondents and their organizational commitment $(p=.045)$

Table (6) Comparison of Mean Scores of Study Sample Sex and Educational Level and Their Communication Satisfaction and Organizational Commitment

\begin{tabular}{|l|l|l|l|l|l|l|l|l|}
\hline $\begin{array}{l}\text { Demographic } \\
\text { characteristics }\end{array}$ & \multicolumn{4}{l|}{ Communication satisfaction } & \multicolumn{4}{l|}{ Organizational commitment } \\
\hline & $\mathrm{X}$ & $\mathrm{SD}$ & $\mathrm{T}$ & $\mathrm{p}$ & $\mathrm{X}$ & $\mathrm{SD}$ & $\mathrm{t}$ & $\mathrm{p}$ \\
\hline 1. Sex & & & -.389 & .698 & & & -.482 & .631 \\
-Male & 85.8182 & 20.24761 & & & 37.0606 & 5.29114 & & \\
-Female & 87.1522 & 15.54146 & & & 37.5435 & 4.80708 & & \\
\hline 2. Educational level & & & .781 & .436 & & & -1.629 & .106 \\
-Baccalaureate & 88.1071 & 15.41036 & & & 36.6250 & 4.72349 & & \\
-Master & 85.7391 & 17.94899 & & & 38.0580 & 5.02021 & & \\
\hline
\end{tabular}

Table (6) shows that there is no statistical significant differences between clinical instructor's communication satisfaction and their $\operatorname{sex}(p=.698)$ and educational level $(p=.436)$. Also, the table shows that there is no statistical significant differences between clinical instructor's organizational commitment and their sex $(\mathrm{p}=.631)$ and educational level $(\mathrm{p}=.106)$

Table (7) Correlation between Clinical Instructors Satisfaction with the Current Position and Their Communication Satisfaction and Organizational Commitment

\begin{tabular}{|c|c|c|c|c|}
\hline \multirow{3}{*}{$\begin{array}{l}\text { Satisfaction with the current } \\
\text { position }\end{array}$} & \multicolumn{2}{|c|}{ Communication satisfaction } & \multicolumn{2}{|c|}{ Organizational commitment } \\
\hline & $\mathrm{R}$ & $\mathrm{P}$ & $\mathrm{r}$ & $\mathrm{P}$ \\
\hline & .700 & .000 & .520 & .000 \\
\hline
\end{tabular}

This table represents the correlation between the satisfaction of clinical instructors with their current position and their communication satisfaction and organizational commitment. It is clear from this table that there is a statistical significant correlation between clinical instructor's satisfaction with the current position and both of communication satisfaction and organizational commitment $(\mathrm{p}=.000)$

\section{Discussion}

Communication is a vital process in every organization. People at work spend a great deal of time communicating with each other in meetings, over the phone, via e-mail, etc. Communicating effectively means being able to send a message across the organization that is easy to understand and accurate. When communication flows accurately and effectively, the organization will run smoothly. However, if there is a breakdown in the flow of communication, or the information is not accurate, the organization is likely to 
encounter performance problems. Communication satisfaction among the employees within the organization may also affect the organizational commitment. From this point of view, the organizational commitment and internal communication satisfaction of the employees is one of the most important values of the organizations (Engin, 2013).

It is crucial to study whether communication satisfaction changes in this current workforce, where technology plays an important role on how the organization connects with their employees. It is important for employees to feel connected and informed about the organization's progress, to promote organizational commitment. So the aim of this study was to investigate the relationship between clinical instructor's communication satisfaction and their organizational commitment.

It has been found that there is a significant positive relationship between communication satisfaction and organizational commitment among clinical instructors. This result is confirmed by (Engin, 2013) who reported that the more satisfied employees are with communication the more committed they are to the organization and vice versa. Furthermore, there is a statistical significant correlation between clinical instructor's organizational commitment and communication satisfaction subscales. The researches that supported this finding include Ahmad (2004) and Alanezi (2011). The relationship is strong among these two variables, as reported by the previous researches. They found a strong relationship between the subscales of communication satisfaction and employees organizational commitment.

It was found that communication satisfaction had a greater impact on organizational commitment, where it can better predict the organizational commitment level among the clinical instructors based on their level of communication satisfaction. This means that if communication satisfaction is high, we can predict that organizational commitment is high as well. The study showed that there is a statistical significant correlation between clinical instructor's organizational commitment and all the subscales of communication satisfaction. This finding is confirmed by a study done by Ahmed (2004) who reported that as communication satisfaction has a stronger impact on organizational commitment, thus each subscale in communication satisfaction is being examined to identify the significant subscale. He found that communication subscales had a greater impact on employee's commitment.

In terms of gender differences, female scored a considerably higher mean score as compared to male. Female scored 37.54 in organizational commitment while male scored a mean of 37.06. Based on mean score, it can be seen that female tend to have a higher organizational commitment as compared to male. The results revealed that there is no significant difference between male and female in organizational commitment, while female tends to have higher organizational commitment. This implies that it is important for managers to focus on improving the communication satisfaction level of male employees which in turn will increase organizational commitment level. This finding is confirmed by Clayton, Petzall, Lynch and Margaret (2007) and Khalili and Asmawi (2012), who found that female tend to have higher organizational commitment than male.

In terms of age differences, respondents in the age group of above 30 scored the highest mean score at 39.06 , followed by the age group less than 25 years old at 37.20 and 36.80 for age group of 25-30 years old, for organizational commitment. This implies that it is important for managers to focus on improving the communication satisfaction level of younger employees, which in turn will increase their organizational commitment. These findings were supported by the study done Kaur and Sandhu (2010), who reported that older workers tend to have higher organizational commitment due to the changes in their environment and life experiences.

Moreover, results indicated that there is no correlation between the years of clinical instructor's experience in the faculty and years of experience in their current position and organizational commitment. This finding is supported by (Yan.2011) who reported that the correlations between demographics and organizational commitment were not strong.

\section{Conclusion}

The findings of the present study indicated that there is a positive correlation between clinical instructor's communication satisfaction and their organizational commitment. A statistical significant correlation was found between clinical instructor's satisfaction with their current position and communication satisfaction and their organizational commitment. Furthermore, the results indicated a statistical significant correlation between clinical instructor's communication satisfaction and their years of experience in the faculty and years of experience in the current position.

\section{Recommendations}

Based on the findings of the present study the researchers recommended the following:

1. This research should be replicated in the governmental and educational organizations.

2. Organizations can improve communication by providing opportunities for training programs and workshops for continues improvement with the focus on effective communication. 
3. Organizations can work on planning more meetings with clearly written minutes from meeting discussion, and also publishing monthly newsletter, to ensure that clinical instructors are well informed about organization's direction.

4. The organization's leaders should develop strategies and update policies and procedures by adding clear information and updates based on the needs and areas of concern, to keep clinical instructors wellinformed.

5. Future research studies should be conducted to investigate the relationship between communication satisfaction and other variables as job satisfaction, turnover and productivity.

\section{References}

[1]. Ahmad, A. H. (2004): Relationships between communication satisfaction and organizational commitment of academic staff in selected public university. Doctorate Thesis: University Putra Malaysia.

[2]. Alanezi, A. S. (2011): Communication satisfaction and its relationship to organizational commitment among secondary teachers in Kuwait. Doctorate Thesis: Indiana State University.

[3]. Balakrishnan, C and Masthan, D. (2013): Impact of Internal Communication on Employees Engagement: A Study at Delhi International Airport. International Journal of Scientific and Research Publications, 3(8), 1-13

[4]. Baumruk, R., Gorman, B., \& Gorman, R.E. (2006): Why managers are crucial to increasing engagement. Strategic HR Review, $5(2), 24-27$

[5]. Bourque, j. (2009): The effects of organizational communication on job satisfaction and organizational commitment in a land ambulance service and the mediating role of communication satisfaction. Career Development International, 14 (1), 29 - 49

[6]. Carr, G. (2005): Investigating the motivation of retail managers at a retail organization in the Western Cape. Degree Mini-Thesis. University of the Western Cape.

[7]. Carriere, J. \& Bourque, C. (2009): The effects of organizational communication on job satisfaction and organizational commitment in a land ambulance service and the mediating role of communication satisfaction. Career Development International, 14 (1), $29-49$. Retrieved October 12, 2012, from Emerald Database.

[8]. Clayton, B., Petzall, S., Lynch, B. \& Margret, J. (2007): An examination of the organizational commitment of financial planners. International Review of Business Research Papers, 3 (1), 60-72

[9]. Communication theory.org, (2010): Communication theory: Kinds (Types) employed by business organisations. Retrieved on July 2014

[10]. DeBussy, N., Ewing, M., \& Pitt, L. (2003): Stakeholder theory and internal marketing communications: A framework for analysing the influence of new media. Journal of Marketing Communications, 9, 147-161

[11]. De Ridder \& Jan A., (2004): Organizational communication and supportive employees. Human Resource Management Journal, 14(3), 20-30

[12]. Downs, C. \& Hazen, M. (1977): A Factor Analysis Study of Communication Satisfaction, Journal of Business Communication, 14: 63-74

[13]. Engin,E. (2013): The effect of communication satisfaction on organizational commitment. British Journal of Arts and Social Sciences. 14. 109-124

[14]. Farahbod.F, Salimi.S and Dorostkar. K.(2013): Impact of Organizational Communication in Job Satisfaction and Organizational Commitment. Interdisciplinary Journal of Contemporary Research in Business. 5(4), 4-19

[15]. Goodman, J., \& Truss, C. (2004): The medium and the message: communicating effectively during a major change initiative. Journal of Change Management, 4(3), 217-228

[16]. Hayase, L. (2009): Internal communication in organizations and employee engagement. Master Thesis. University of Nevada, Las Vegas

[17]. Iqbal, A. (2010): An Empirical Assessment of Demographic Factors, Organizational Ranks and Organizational Commitment. International Journal of Business and Management. 5(3), 16-27

[18]. Khalili, A. \& Asmawi, A. (2012): Appraising the impact of gender differences on organizational commitment: empirical evidence from a private SME in Iran. International Journal of Business and Management, 7 (5), 100-110

[19]. Kaur, K. \& Sandhu, H. S. (2010): Career stage effect on organizational commitment: Empirical eveidence from Indian banking industry. International Journal of Business and Management, 5 (12), 141-152

[20]. Lew, T. Y. (2011): Affective organizational commitment and turnover intention of academics in Malaysia. International Conference on Business and Economic Research, 1, 110-114

[21]. Liang, Q and Back, K. (2011): Communication Satisfaction in the Hospitality Industry: A Case Study of Employees at a Theme Park in China.

[22]. Miller, K. (2015): Organizational communication: Approaches and process (7th ed.). Stamford, CT: Cengage Learning

[23]. Mowday, R. T., Steers, R. M., \& Porter, L. W. (1979): The measurement of organizational commitment. Journal of Vocational Behavior, 14, 224-247

[24]. Moyer, J. (2011): Employee/organizational communications. Institute for Public Relations. Retrieved on March 12, 2014, from

[25]. Newstrom, J. W. (2007): Organizational Behaviour-Human Behaviour at work (12th ed). New York: McGraw Hill International Edition.

[26]. Sharma, P (2015): Organizational Communication: Perceptions of Staff Members' Level of Communication Satisfaction and Job Satisfaction. East Tennessee State University

[27]. Steingrimsdottir, H. (2011): The relationship between internal communication \& job satisfaction: A case study. Copenhagen Business School: Marketing Communication Management. Retrieved on March 15, 2014

[28]. Yan,W. (2011): The Role of Communication in Enhancing Employees'Organizational Commitment: Exploring the Relationship between Social-emotional-oriented Communication, Work-oriented Communication and Organizational Commitment in China. Master Thesis. Uppsala University.

[29]. Yates, K. (2006): Internal communication effectiveness enhances bottom-line results. Journal of Organizational Excellence, Summer, 71, 79- 93

[30]. Zhen, Y. (2013): The Impact of Communication Satisfaction and Emotional Exhaustion on Organizational Commitment. Master Thesis. Universiti Tunku Abdul Rahman. 